Moon (at Full) rises, 16h. 43m.; souths, oh. 25m.*; sets, 8h. $14 \mathrm{~m} .{ }^{*}$; decl. on meridian, $17^{\circ} \mathrm{r}^{\prime} \mathrm{N}$.

\begin{tabular}{|c|c|c|c|c|c|c|c|}
\hline Planet & & $\begin{array}{l}\text { Rises } \\
\text { h. m. }\end{array}$ & & $\begin{array}{l}\text { Souths } \\
\text { h. m. }\end{array}$ & & $\begin{array}{c}\text { Sets } \\
\text { h. m. }\end{array}$ & Decl. on meridian \\
\hline Mercury & & 932 & $\cdots$ & 139 & $\cdots$ & 1646 & $25^{\circ} 32 \mathrm{~S}$. \\
\hline Venus & $\ldots$ & II 28 & $\ldots$ & 158 & $\ldots$ & 1848 & $2513 \mathrm{~S}$. \\
\hline Mars & $\ldots$ & $233 \mathrm{I}^{*}$ & $\ldots$ & 631 & $\ldots$ & I3 3I & I0 $54 \mathrm{I}$ \\
\hline Jupiter & $\ldots$ & I 53 & $\ldots$ & 80 & $\ldots$ & 147 & $\circ 40 \mathrm{~N}$. \\
\hline Saturn & $\ldots$ & I8 $19^{*}$ & $\ldots$ & 227 & $\ldots$ & I0 35 & $\ldots \quad 2221 \mathrm{~N}$ \\
\hline
\end{tabular}

* Indicates that the rising is that of the preceding and the southing and setting those of the following day.

Occultations of Stars by the Moon

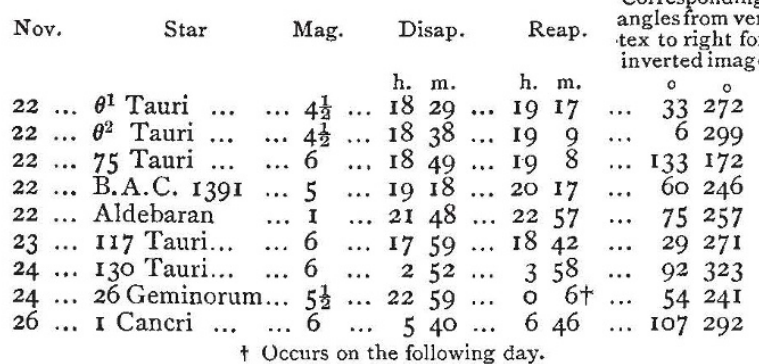

For further particulars in regard to the occultation of Aldebaran see NATURE, vol. xxxii, p. 610.

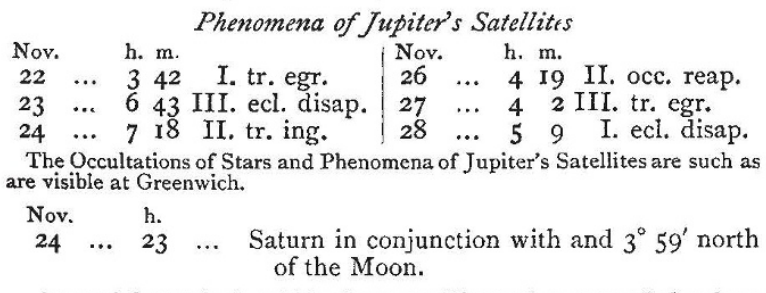

A special watch should be kept on November 27 and the days immediately preceding and following, in order to note whether there is any recurrence of the meteoric shower observed on November 27, 1872, and believed to be connected with Biela's comet. The radiant point is near $\gamma$ Andromedæ.

\section{CHEMICAL NOTES}

IN order to obtain constant temperatures easily maintained and completely under control, Messrs. Ramsay and Young (C. S. Fourmal, Trans., 1885, 640) employ vapours of the following compounds, and alter the pressure to which each vapour is subjected : carbon disulphide, ethyl alcohol, chlorobenzene, bromobenzene, aniline, methyl salicylate, bromonaphthalene, and mercury. By the use of the vapours of these bodies at various pressures, any desired temperature between that of the atmosphere and $360^{\circ}$ can be easily obtained. The authors have very carefully determined the vapour-pressures of these compounds for a large range of temperature. The methods of experiment are fully described, and the results are presented in the form of tables, which must prove of much service to those chemists and physicists who have occasion to raise pieces of apparatus to a known temperature, to vary that temperature if required, or to keep it perfectly constant for an indefinit a period.

As was noticed in these columns some time ago, Dixon has recently proved that a mixture of perfectly dry carbon monoxide and oxygen is not exploded by the passage of electric sparks; but that the presence of a minute quantity of water suffices to determine the combination of the gases. Dixon supposed that the action of the water was as represented in the following two equations :-

$$
\begin{aligned}
& \text { (I) } \mathrm{CO}+\mathrm{H}_{2} \mathrm{O}=\mathrm{CO}_{2}+\mathrm{H}_{2} \text {, } \\
& \text { (2) } 2 \mathrm{H}_{2}+\mathrm{O}_{2}=2 \mathrm{H}_{2} \mathrm{O} \text {. }
\end{aligned}
$$

Now Traube (Ber. IS, I890) has shown that carbon monoxide does not decompose water in complete absence of air or oxygen, even at very high temperatures; he has also shown that when moist carbon monoxide and oxygen are exploded together, hydrogen peroxide is an invariable product. Traube suggests that the following three changes probably occur during the explosion in question :-

(1) $\mathrm{CO}+2 \mathrm{H}_{2} \mathrm{O}+\mathrm{O}_{2}=\mathrm{CO}(\mathrm{OH})_{2}+\mathrm{H}_{2} \mathrm{O}_{2}$.

(2) $\mathrm{CO}+\mathrm{H}_{2} \mathrm{O}_{2}=\mathrm{CO}(\mathrm{OH})_{2}$.

(3) $2 \mathrm{CO}(\mathrm{OH})_{2}=2 \mathrm{CO}_{2}+2 \mathrm{H}_{2} \mathrm{O}$.

When hydrogen is burnt in moist oxygen, hydrogen peroxide is always produced, according to Traube. Whether a perfectly dry mixture of hydrogen and oxygen could or could not be exploded by electric sparks cannot be regarded as settled; Traube thinks that such a mixture would prove to be non-explosible. $\mathrm{He}$ regards the mutual action of hydrogen, oxygen and water as in all respects comparable with that of carbon monoxide, oxygen, and water, or with that of zinc, lead, and some other metals, oxygen, and water. The changes which occur in the explosion of moist hydrogen and oxygen are formulated by Traube thus :-

(I) $\mathrm{H}_{2}+2 \mathrm{H}_{2} \mathrm{O}+\mathrm{O}_{2}=2 \mathrm{H}_{2} \mathrm{O}+\mathrm{H}_{2} \mathrm{O}_{2}$.

(2) $\mathrm{H}_{2} \mathrm{O}_{2}+\mathrm{H}_{2}=2 \mathrm{H}_{2} \mathrm{O}$.

The occurrence of the second part of this reaction has been experimentally demonstrated by Traube.

IN continuing his experiments on nitrification, Warington (C.S. Fournal, Trans. 1885, 758) has shown that the limit of concentration (about 12 per cent.) beyond which urine ceases to be nitrifiable under ordinary conditions may be largely extended by adding gypsum to the liquid. A solution containing 50 per cent. of urine, and 22 milligrams of gypsum for every c.c. of urine, began to nitrify after about five months; solutions containing 15,20 , and 30 per cent. of urine began to nitrify after the lapse of 53, 68, and 78 days respectively. The gypsum prevents the accumulation of ammonium carbonate in the liquid.

J. H. VAN'T HOFF describes (Berichte, xviii. 2088) experiments on phenomena, analogous to those exhibited by gases at their "critical points," occurring during chemical decomposition. Phosphonium chloride, $\mathrm{PH}_{4} \mathrm{Cl}$, which melts at $25^{\circ}$, was heated to $50^{\circ}-5 \mathrm{I}^{\circ}$ at a pressure of $80-90$ atmospheres in a Cailletet's apparatus; under these conditions the line of separation between liquid and vapour disappeared, and, on cooling, the formation of nebulous streaks became plainly visible. It is well known that the vapour obtained by heating $\mathrm{PH}_{4} \mathrm{Cl}$ under ordinary conditions consists of $\mathrm{PH}_{3}+\mathrm{HCl}$; it is not possible to say to what extent the melted substance in van't Hoff's experiment consisted of a compound of $\mathrm{PH}_{3}$ and $\mathrm{HCl}$, and the gaseous part consisted of a mixture of these constituents, yet it seems certain that, when $\mathrm{PH}_{4} \mathrm{Cl}$, a compound which is chemically decomposed when vaporised, is heated to $50^{\circ}$ under a pressure of $80-90$ atmospheres, there exists identity between the vapour and the condensed portion of the body.

LA CosTe describes (Berichte, xviii. 21 22) a modification of V. Meyer's apparatus whereby the densities of easily decomposed compounds may be determined at low temperatures under smal pressures.

\section{GEOGRAPHICAL NOTES}

A CATALOGUE of the printed maps, plans, and charts in the British Museum has been prepared by Prof. Douglas, and will be issued in two large volumes. It represents the contents of the manuscript catalogue in 323 volumes, the catalogue of the maps and plans in the Royal Library in two printed volumes, and the manuscript catalogue of charts in the same library. The original manuscript catalogue was made inder the superintendence of Mr. Major, late Keeper of the Department of Maps. The orthography adopted in the present catalogue is that used in Keith Johnston's "General Dictionary of Geography," with the exception of India, for which Hunter's "Gazetteer" has been taken as a guide. The utility of this catalogue to the geographical student will be found in the comparatively simple alphabetical arrangements for the heading; of countries and places, combined with the names of geographical writers, which last often serve a; short cuts to any particular atlas or map. Thus, under the head of "Ptolemy," the pillar and foundation of ancient geography, there are seventy-four entries referring to the various editions and copies of his "Geographica." Turning to the names of the fathers of modern geography, Ortelins and Mercator, we find under the former twenty-nine entries describing the various copies and editions of his "Theatrum orbis Terrarum." The geographical labours of his contemporary and friend, Mercator, will be best realised by a reference to the 